\title{
An Applied Approach to Teaching HR Concepts Using an ERP System
}

\author{
Paul Hawking \\ Victoria University, \\ Melbourne, Australia
}

Paul.Hawking@vu.edu.au

\author{
Susan Foster \\ UNITEC, Auckland, \\ New Zealand \\ ter@optusnet.com.au
}

Penny Bassett

Victoria University,

Melbourne, Australia

\section{Abstract}

Enterprise Resource Planning (ERP) systems offer a software-based system that handles an enterprise's total information system needs in an integrated fashion. These systems are purported to incorporate "best business practice". Many universities have realized the potential of these systems as educational tools and have developed curriculum accordingly. Many companies in recent times have identified the benefits of the Human Resources functionality offered by ERP systems. However universities in Australia have not realized the potential of this functionality as a teaching tool to reinforce many of the concepts covered in a Human Resource Management curriculum. This paper outlines the experiences at Victoria University where SAP Human Resources functionality was incorporated for the first time. It also describes a number of student projects under development that will enhance this curriculum development. The paper will provide a model to other universities who are considering developing similar type of curriculum. .

\section{Introduction}

Human Resource Management (HRM) has evolved from an administrative function to a strategic role that can add value to an organisation. A major focus of HRM is now seen in developing organisations and systems for managing change to increase competitiveness. Most universities around the world have realised the importance of HR and have developed curriculum focusing on personnel or HR management. Human Resource educational programs can be traced back to the late 1910's when courses in personal management first appeared at Dartmouth University. Kaufman's (1999) paper traces the evolution of university HR programs and identifies a number of characteristics of HR management and the impact these are having on today's HR curriculum. One of these, is the impact of technology and the inability of academia to keep abreast of issues associated with this impact. In accordance with this, he believes there is a significant gap between the skills and competencies of graduates and those required by industry. A report conducted by IBM and Towers-Perrin (1999) surveyed 3,000 HR professionals, consultants and academics in an attempt to identify key HR competencies. One key competency identified was the level of computer literacy of HR professionals. The question needs to be asked what are the key technological skills and how are universities responding to provide appropriate educational experiences for graduates. A literature search failed to identify any research on the appropriate technological skill sets for HR management graduates.

Material published as part of these proceedings, either on-line or in print, is copyrighted by Informing Science. Permission to make digital or paper copy of part or all of these works for personal or classroom use is granted without fee provided that the copies are not made or distributed for profit or commercial advantage AND that copies 1) bear this notice in full and 2) give the full citation on the first page. It is permissible to abstract these works so long as credit is given. To copy in all other cases or to republish or to post on a server or to redistribute to lists requires specific permission from the publisher at Publister@intormingscience.org

\section{ERP Systems}

There has been a plethora of attention given to the impact of the Internet on the commercial activities of business. However an increasing number of researchers believe that the adoption of Enterprise Resource Planning (ERP) systems by business may 
be the most important use of information technology (Davenport 1998).

ERP systems are modular application software that helps businesses increase their productivity of such mission-critical components as human resources, finance, parts purchasing, inventory control, supply chain and customer relationship management. The software infrastructure facilitates the flow of information between all functions within the business. This infrastructure is built upon a common database responsible for storing all of the data from processes that are essential for business operations and decision making. ERP systems are enterprise-wide and they claim to incorporate best business practices that replace separate functional systems and impact significantly on the existing processes and practices of business.

ERP sales represent a significant proportion of total outlays by business on information technology infrastructure. It has been estimated that worldwide expenditure on ERP software was \$16.6 billion in 1998 and that the ERP market will sustain strong growth to reach an annual revenue of \$66.6 billion in 2003 (Busse 1999). The main ERP vendors are SAP, Oracle, Peoplesoft and JD Edwards. SAP is the leading ERP vendor with approximately 25,000 employees, 15,000 customers, and 1.7 million users worldwide (SAP 2002). SAP's ERP system, referred to as SAP R/3 has approximately $39 \%$ of the world ERP market. In Australia there are approximately 300 companies using SAP R/3 representing a broad range of industries and organisations such as automotive, consumer products, chemical, manufacturing, oil and gas, high-tech pharmaceutical, and communications (Hawking and Stein 2001). Of these 320 companies 150 have implemented the HR module. A survey (Watson Wyatt 2000) of 295 American companies found that approximately 50\% used an ERP system to support their HR management and payroll activities. Worldwide there are 6,500 companies that use SAP to support their HR functions (IDC 2001).

A major issue with ERP systems is the time required for their implementation. Depending upon the size of the business and the number of modules being implemented, the full implementation process can extend to five years and cost hundreds of millions of dollars. A major contributing factor to these high costs is the expense associated with implementation consultants who are in short supply world-wide. This was reflected in a survey by Hewitt Associates (1999) which found that people with ERP skills are in short supply, high demand, and experiencing rapid changes in their market value. While in Australia, an IT Skills Shortage study (1998) commissioned by the Government found skill shortages in enterprise wide systems and more specifically SAP R/3 and PeopleSoft, implementation and administration. The Department of Immigration and Multicultural Affairs in their Migration Occupations in Demand List (MODL 2000) identified information technology specialists with SAP R/3 skills as people who would be encouraged to migrate to Australia.

This lack of skills is even more applicable to HR module implementations as HR issues tend to be country specific and have added complexities of a variety of payroll structures. In addition to this HR is often given a lower priority in terms of resources to other business areas in the ERP implementation. (Walker 2002; Stambaugh 1999)

\section{Universities and ERP Systems}

Many universities have identified the value of incorporating ERP systems into their curriculum. ERP systems can be used to reinforce many of the concepts covered in the business discipline (Becerra-Fernandez et al, 2000; Hawking, Shackleton and Ramp 2001). The vendors argue that their products incorporate "world's best practice" for many of the business processes they support making them an ideal teaching tool (Hawking et al, 1999; Watson and Schneider, 1999).

Even though the value of including ERP systems into the curriculum has been identified, there are a number of barriers preventing this from happening. One significant hurdle is the limited knowledge and experience of academic staff charged with the responsibility of integrating ERP curriculum into their courses. ERP systems are complex and the time required for developing curriculum is far in excess to 
what staff have experienced for curriculum development in other areas. Those who develop the necessary understanding of a particular ERP system to develop curriculum can be lured away from the university into lucrative jobs in private industry. The shortfall of academic skills and experience is further compounded by the limited access to relevant ERP professional development activities and the continual upgrade of the ERP software. Another significant barrier to the use of ERP systems in universities is the perceived need for students to gain "hands-on" experience to master the concepts inherent in these types of systems (Watson et al, 1999). In the past, if a university decided to incorporate a major software product into its curricula, it would have purchased the software and set up the necessary infrastructure to support it. ERP systems themselves are expensive but there are the additional associated costs of hardware and professional development for the computer support staff together with the necessary incentives to retain these people once they are skilled. Many universities find that the barriers associated with introducing ERP systems are just too great!

An increasing number of universities are investigating strategic alliances with ERP system vendors to provide the support for incorporating ERP knowledge into their curriculum (Hawking 1998). The ERP vendor benefits from these alliances by increasing the supply of skilled graduates that can support their product thereby enhancing its marketability and lowering the cost of implementation.

The SAP University Alliance Program in Australia is an example of a strategic alliance between a number of universities and an ERP vendor. As part of its University Alliance, SAP provides their R/3 software and technical and professional support for the integration of the ERP system into the curriculum.

However it is still the responsibility of individual academics to develop the necessary curriculum and the university to provide the necessary infrastructure to support the system. This is reflected in the diversity and extent of curriculum activities of the universities involved in the alliance. A survey of these universities indicated that some were struggling to offer any ERP related subjects while others offered numerous subjects over many disciplines (Gable and Rosemann, 1999). However none of the universities had used the ERP system to support their HR curriculum.

ERP systems incorporate "state of the art" technology and have extensive functionality to support HR management including knowledge management, data warehousing and web enabled technologies such as employee kiosks and online recruitment. The HR module is integrated with the other business functional areas rather than being treated as a stand alone function. However the lack of inclusion of the HR system to reinforce HR concepts does not appear unique to ERP systems. When reviewing literature associated with the teaching of HR management very little attention was given to the information systems which support this function. In a study (Gibb Dyer, 1999) which compared three graduate programs which had a HR management focus it appeared that none of them had any required units of study which had a technological focus.

\section{HR Teaching Example}

Victoria University joined the SAP University Alliance in 1998. It adopted a faculty approach to the incorporation of ERP systems into business curriculum rather focussing on one particular department. Since joining the Alliance the University has developed a Graduate Certificate, Graduate Diploma and Masters of Business in Enterprise Resource Planning Systems as well as incorporating SAP R/3 into several undergraduate and postgraduate subjects. Currently we have 15 staff teaching more than 20 subjects at both the undergraduate and post graduate levels to approximately 1,000 students. Our programs are also exported in the Asian region using a e-learning model (Hawking and McCarthy 2001).

The faculty offers undergraduate and postgraduate HR management programs that incorporate HR information systems subjects. However it has only been recently that the staff involved in these programs have taken up the opportunity to use an ERP system to support their teaching. The remainder of this paper will outline how the SAP R/3 was used in HR curriculum and future initiatives. 
The Human Resource Information Systems unit is a core unit in the Bachelor of Business in Human Resource Management and taught 400 students across 2 campuses. A similar unit is taught at the postgraduate level. Previously staff used a stand alone HR system which required a new licensing agreement for the upcoming year. Due to the focus on SAP across the faculty it was decided to trial this software in the unit in 2001. The unit involved a 2 hour lecture and 1 hour workshop for 13 weeks.

The purpose of the workshops were to introduce students to the complexity of these types of systems and gain an understanding of how these systems supports key HR functions. It was expected that students would gain a basic comprehension of implementation issues, HR master data and reporting options.

Students were first introduced to SAP R/3 through a series of exercises that reinforced navigation techniques and accessing the help documentation through a variety of methods. They then viewed the material master for a product in the system and created a number of reports where they performed simple calculations and demonstrated the concept of "drilling down". Once the basic concepts were mastered then students focused on the HR module.

To support the teaching, a fictitious case study was developed based on a bicycle company. Students were provided with the company's organisational structure including organisational units, job profiles and positions. Each student was required to map the company structure into the SAP system. They gained an understanding of the enormity of this implementation task in relation to large corporations and the work required in maintaining position descriptions and job profiles.

Once the structure of the company was created students were introduced to the recruitment process. This involved: creating a vacancy based on the positions they had previously created. They then created the vacancy advertisement including content and medium. They entered data relating to the received applications and then used the system to match the applicants to the position description. Letters of acceptance and rejection were drafted and using SAP's interface with Microsoft Word created a merged letters for each applicant. Master data was then entered into the system for the successful applicant as part of the hiring process.. Each stage of the recruitment process required the students to perform actions within the SAP system and enter the appropriate master data items.

The SAP system has more than 15,000 reports available to users. The reports are can be accessed through a variety of methods including, a hierarchical menu structure, an organisational structure graphic and ad hoc queries. Students produced a number of reports using these methods. These reports, other demonstrating the capabilities of the system were used as an assessment method reflecting each student's work.

Initially the students found the ERP system complex and confusing but after a few workshops they began to grasp some of the basic concepts. It is believed that this was partly due to students being provided with a step-by-step tutorial in the workshop and then having exercises to complete in their own time which were similar to the workshop task. This encouraged students to understand the process rather than mindlessly following the steps.

An added benefit of the using the ERP system was that many students received positive feedback from industry. As part of their assessment they were required to complete a case study on a company's HR system and then present their findings to the remainder of the class. Many of the case studies involved an ERP system, especially SAP R/3. Often students informed their industry contacts that they were working with a similar system and the value of these skills were highlighted to the students. This also illustrated the calibre of our students and curriculum activities to industry.

The trial was considered successful even though there was considerable amount effort required in developing the workshop exercises. A shortcoming of the teaching was the use of the demonstration system within $\mathrm{R} / 3$. SAP R/3 is provided with a fully populated database which reflects a sample company (IDES) to demonstrate the capabilities of the system. In the HR module, the screens reflect a German example with data fields relevant to that country. It was felt that students learning would be enhanced if 
Australian examples were used. Through a curriculum innovation grant a group of graduate information systems students in consultation with SAP will be implementing the Australian version of HR in the next 6 months.

It is envisaged that this will be extended to include SAP's HR portal technology. This will be used to demonstrate to students how web enabled technology is being applied to HR functions. At the graduate level the curriculum will focus on the strategic functionality of the HR module including the advanced reporting features such as the Managers Desktop.

\section{Conclusion}

It is important for students to feel that their education is unique and of value. The use of an ERP system to teach HR concepts meets these criteria. Although the development of curriculum using an ERP system requires an enormous amount of work the outcomes justify it. Our use of SAP R/3 in the area of HR was only a starting point and provides the foundations for some exciting and innovative curriculum.

Hopefully other ERP alliance universities around the world will realise the potential of using these systems to reinforce HR concepts.

\section{References}

Becerra-Fernandez, I., Murphy, K. E. and Simon, S. J. (2000) "Enterprise resource planning: integrating ERP in the business school curriculum" Communications of the ACM, Volume 43, No. 4, April, Pages 39 - 41

Busse, T.,(1999) "ERP market will reach $\$ 66$ billion by 2003, AMR says", InfoWorld Electric, August,

Davenport, T.H., (1998)“Putting the Enterprise into the Enterprise System”. Harvard Business Review,. July-August.

Gibb Dyer W.,(1999) “Training Human Resource Champions For The Twenty Century”, Human Resource Management Journal, Vol. 38, No. 2, Summer.

Hawking Paul, Stein Andrew,(2001) “An Insight into the Australian ERP Market”, Proceedings of ICIES 2001, Portugal.

Hawking P, Adrian Ramp, Peter Shackleton, (2001) "IS'97 model curriculum and enterprise resource planning systems" Business Process Management Journal, Vol.7 No. 3.

Hawking Paul, McCarthy Brendan, (2001) “A Model for Delivering ERP Education over the Internet”, SAP Curriculum Congress San Diego.

Hawking, P. (1999) "The Teaching Of Enterprise Resource Planning Systems (Sap R/3) In Australian Universities" in Proceedings of 9th Pan Pacific Conference, 31 May-2 June, Fiji.

Hewitt Associates, (1999) Hot Technology Study: Scarcity of IT Professionals Means Big Pay Raises, retrieved May 2000 from the World Wide Web nttp://www.hewitt.com/compsurveys.

IBM/Towers-Perrin,(1999) Priorities For Competitive Advantage, a $21^{\text {st }}$ century vision: A Worldwide Human Resources Study, Towers-Perrin, New York.

IDC Report (2001) Worldwide Human Resources Management and Payroll Applications Market Results and Forecast, 20002005, retrieved January 2002 from the World Wide Web http://www.idc.com/en_USt.

Kaufman B. E.,(1999) "Evolution And Current Status Of University HR Programs", Human Resource Management Journal, Vol. 38, No. 2, Summer.

MODL (2000) Migration to Australia - Skilled Migration, Migration Occupations in Demand List, retrieved May 2001 from the World Wide Web http://www.immi.gov.au/allforms/modt.htm.

SAP, SAP Corporate Overview, retrieved January 2002 from the World Wide Web http://www.sap.com/company/publications/ts_corp_over.asp

Stambaugh R. H.,(1999) "Post-Modern HR Systems (Part 2)”, IHRIM Journal, June.

Walker A., "How the Web Will Change The Structure Of HR", retrieved January 2002 from the World Wide Web http://www.workforce.com/archive/teature/22/28//6/1ndex.php, 
Watson, E. and H. Schneider, (1999) "Using ERP Systems in Education". Communication of the Association for Information Systems, 1(9).

Watson Wyatt, (2001) “The Net Effect: e-HR And The Internet,” Watson Wyatt Worldwide 2000, retrieved January 2002 from the World Wide Web http://Www.watsonwyatt.com/research/resrender.asp?id=W-319\&page=1.

\section{Biographies}

Paul Hawking is a lecturer in the School of Information Systems at Victoria University, Melbourne, Australia. He is the SAP Academic Program Director for the Faculty of Business and Law and is responsible for the facilitation of ERP education across the university. He has been involved in education delivery and curriculum development for the past twenty years and has co-authored a series of computer texts. He is currently Chairperson of the Australian SAP User Group.

Susan Foster is an Information Systems lecturer at UNITEC, Auckland, New Zealand. She is coordinator of the SAP University Alliance Program in her institution. Susan has been involved in education delivery and curriculum development for the past twenty years. Her research focuses on ERP systems and the impact they have on organisations.

Penny Bassett is a lecturer in the School of Management at Victoria University, Melbourne, Australia. She has an ongoing interest in research and teaching in the area of human resource information systems. She is a Member of the Australian branch of International Human Resource Information Management (IHRIM) and was a founding member of the HRIS special interest group of the Australian Human Resources Institute (AHRI). 